06

\title{
Исследование защитных свойств комбинированного металлокерамического материала при высокоскоростном ударе
}

\author{
(c) А.Н. Ищенко, С.А. Афранасьева, Н.Н. Белов, В.В. Буркин, В.М. Захаров, А.И. Зыкова, А.Ю. Саммель, \\ А.Б. Скосырский, Е.Ю. Степанов, А.Н. Табаченко, А.В. Чупашев, О.В. Ушакова, М.В. Хабибуллин, \\ H.T. Югов
}

Научно-исследовательский институт прикладной математики и механики национального исследовательского

Томского государственного университета,

634050 Томск, Россия

ฯ e-mail: s.a.afanasyeva@mail.ru

Поступило в Редакцию 27 июля 2018 г.

В окончательной редакции 25 ноября 2019 г.

Принято к публикации 10 декабря 2019 г.

\begin{abstract}
Проведен анализ баллистической стойкости комбинированного металлокерамического материала на основе высокотвердой керамики в связке с интерметаллидом на высокопрочной металлической подложке $\left(\mathrm{TiB}_{2}+\mathrm{NiTi}\right)+\mathrm{Ti}$, в сравнении с пластинами из стали, титанового сплава ВТ1-0 и корундовой керамики $\mathrm{Al}_{2} \mathrm{O}_{3}$ при соударении со стальным сферическим ударником в диапазоне скоростей порядка $2500 \mathrm{~m} / \mathrm{s}$. Экспериментальные исследования защитных преград при высокоскоростном ударе проведены с применением экспериментального высокоскоростного баллистического стенда. Математическое моделирование проведено в рамках пористой упругопластической среды с учетом различных механизмов разрушения материалов, модифицированной для сред со сложным составом. Показано, что в исследуемом диапазоне скоростей соударения при пробитии преград материал $\left(\mathrm{TiB}_{2}+\mathrm{NiTi}\right)+\mathrm{Ti}$, несмотря на низкую поверхностную плотность, оказывает большее силовое воздействие на ударник и большее сопротивление прониканию, чем сталь, титан и керамика.
\end{abstract}

Ключевые слова: металлокерамический материал, высокоскоростное соударение, эксперимент.

DOI: $10.21883 /$ JTF.2020.06.49284.296-18

\section{Введение}

Разработка легких защитных конструкций повышенной баллистической стойкости является непростой задачей, поскольку часто возникают противоречивые требования с точки зрения стоимости, веса, толщины, доступности материалов, технологичности и т.д. Кроме того, при проектировании необходимо учитывать и спектры угроз, к которым относится, в частности, поражение преград при соударении с высокоскоростными частицами. В последнее время ведутся активные поиски путей повышения баллистической стойкости защитных преград от высокоскоростного соударения.

В качестве перспективного решения для металлических защитных систем отмечается использование многослойных конструкций. Влияние количества слоев и воздушного зазора на баллистические характеристики многослойных стальных преград, подвергнутых высокоскоростному воздействию медного осколочного снаряда, рассмотрено в [1].

Показано, что монолитная преграда менее эффективна, чем разнесенные многослойные преграды. Кроме того, воздушный зазор увеличивает баллистическое сопротивление многослойных преград, особенно, когда ширина воздушного зазора больше половины длины снаряда. Экспериментальное исследование баллистической эффективности монолитных и многослойных стальных преград также описано в работах [2-4]. Указанные преграды подвергались воздействию снарядов различной геометрии. Оценка эффективности производилась путем сравнения предельных скоростей пробития. В работе [5] численно анализируются результаты пробития монолитных преград конечной толщины и простейших конструкций, состоящих из набора отдельных пластин одинаковой толщины из того же материала, что и материал монолитной преграды. В работе [6] экспериментально исследуется разрушение гомогенных и композиционных преград, имеющих средний металлокерамический слой, при взаимодействии с ударниками из сплава ВНЖ-90. Рассмотрение коэффициента эффективности защитных свойств преграды по относительной величине потери скорости при пробитии преград позволяет сделать вывод о более высоких защитных свойствах композиционных преград при скоростях встречи более $1100 \mathrm{~m} / \mathrm{s}$.

Анализ литературных данных $[7,8]$ показывает, что повышение прочности металлических материалов не исчерпало своих возможностей. Так, увеличение механической прочности сплавов на основе титана можно осуществить путем создания наноструктурных состояний.

Принципиальным преимуществом керамических материалов по сравнению с металлами является ряд более высоких эксплуатационных показателей (тугоплавкость, твердость, износостойкость, коррозионная стойкость, изоляционные свойства, т.д.) и возможность при их изготовлении регулирования в широких пределах основных параметров, характеризующих их функциональные 
и конструкционные свойства (плотность, прочность, вязкость и т.п.). Однако высокотвердые керамики содержат большое число концентраторов напряжений (границ зерен, трещин, пор и т.д.), на которых активируется зарождение концентраторов разрушений даже в области упругого деформирования материала. Микроразрушения в таких материалах могут появиться при сжатии под действием девиаторных напряжений. С увеличением интенсивности импульса нагрузки степень разрушений в фазе сжатия резко возрастает, что приводит впоследствии к падению сопротивления растяжению [9].

В работе [10] исследуется эффективность применения различных керамик на примере карбида бора, оксида алюминия и никелида алюминия в качестве дополнительного слоя для защиты стальных преград при ударе вольфрамовым стержнем в диапазоне скоростей $1-5 \mathrm{~km} / \mathrm{s}$. Проведено физическое моделирование процесса высокоскоростного взаимодействия ударника с преградой, и произведена оценка глубины проникания ударника по методике, разработанной на базе гидродинамической модели бронепробития. Отмечена целесообразность использования сложной комбинированной защиты против высокоскоростных стержневых ударников кинетического действия, и выявлены основные характеристики керамик для их эффективного использования в качестве дополнительных элементов защиты.

В [11] изучалось применение металлических матричных композитов (ММК) в многослойной преграде при пробитии ее стрежневым ударником с удлинением 10.6. Рассматривались два типа пластин ММК, которые были изготовлены методом жидкостного прессования: A356/45 wt.\% $\mathrm{SiC}$ с равномерным распределением частиц $\mathrm{SiC}$ и $\mathrm{Al} 7075 / 45$ wt.\% $\mathrm{B}_{4} \mathrm{C}$ с частицами $\mathrm{B}_{4} \mathrm{C}$. Оценка эффективности применяемой бронированной системы ММК была проведена основываясь на глубине проникновения по сравнению с обычной полубесконечной мишенью из мягкой стали. Были проведены как экспериментальные, так и численные исследования, в которых скорость удара составляла более $1.3 \mathrm{~km} / \mathrm{s}$. Анализ результатов показывает, что размещение переднего слоя из керамики обеспечивает определенный выигрыш в защите, размещение другой металлической пластины перед керамическим слоем обеспечивает дополнительное усиление, а замена переднего слоя металла на ММК показывает наилучшую эффективность. При этом отмечается, что для определения преимущества между $\mathrm{SiC}$ и $\mathrm{B}_{4} \mathrm{C}$ требуются дополнительные исследования.

$\mathrm{B}$ [12] представлен полуаналитический подход к изучению баллистического воздействия на двуслойные преграды „керамика-металл“.

Сравнение баллистических характеристик керамик $\mathrm{Al}_{2} \mathrm{O}_{3}$ и $\mathrm{AlN}$ приведено в [13]. Отмечаются преимущества керамики AlN по сравнению с керамикой $\mathrm{Al}_{2} \mathrm{O}_{3}$ в качестве фронтального слоя в двуслойной преграде с тыльным слоем из $\mathrm{Al}_{5} 0_{83}$ для защиты от воздействия $7.62 \mathrm{~mm}$ бронебойных снарядов при боевых скоростях.
Экспериментальная оценка повреждений сотовых сэндвич-структур с фронтальной пластиной из функционального градиентного материала (ФГМ) Al6061/B 4 C при высокоскоростных ударных нагрузках дается в [14]. Испытания на удар проводились с помощью одноступенчатой газовой пушки для образцов с шестью типами фронтальных пластин, для которых варьировалась доля керамики в ФГМ. Образцы с фронтальными пластинами ФГМ показали повышенную эффективность по сравнению с образцами с чистым Al. Состав материала фронтальных пластин ФГМ значительно влиял на режимы и механизмы повреждения, поглощающую способность и ударопрочность сэндвич-структур. Пластины ФГМ с большим содержанием металла проявляли локализованную пластическую деформацию, тогда как композиции с большой долей керамики распространяли ударную нагрузку на большую площадь. Вклад сотового ядра в способность поглощения энергии сэндвич-структурой заключался в пластическом выпучивании стенок ячейки и деформациях бокового дробления.

Анализ литературных источников позволяет сделать вывод, что значительные усилия разработчиков легких защитных конструкций повышенной баллистической стойкости сосредоточены на исследованиях многослойных преград, содержащих керамику. В частности, отмечается, что двуслойные преграды, состоящие из внешнего керамического слоя и тыльной металлической подложки, весьма эффективны при защите от действия бронебойных снарядов, обладающих высокой проникающей способностью [15]. Теоретическому определению предельной скорости пробития двуслойных керамикометаллических защитных преград с учетом структурных характеристик преграды и физико-механических свойств материалов ударника и преграды посвящены работы $[16,17]$. При этом получены аналитические формулы для расчета предельной скорости пробития таких преград, с помощью этих формул выполнено исследование их баллистической стойкости. В диапазоне поверхностной плотности преграды $30-50 \mathrm{~kg} / \mathrm{m}^{2}$ для разных материалов подложек (органопластик, алюминиевый сплав, титановый сплав, сталь) определены оптимальные относительные толщины керамического слоя, обеспечивающие максимальную предельную скорость пробития.

Компьютерное моделирование является незаменимым инструментом, помогающим баллистическому проектировщику решить эту сложную задачу оценки баллистической стойкости разрабатываемых защитных конструкций за разумное время и с доступными ресурсами [18].

Наряду с имеющимися лицензионными пакетами программ, такими как ANSYS/LS-DYNA, AUTODYN®, ABAQUS и др. разрабатываются новые численные методики описания процессов ударного взаимодействия. Так, предложенная в [19] численная методика в трехмерной постановке позволяет моделировать процессы пробития многослойных и разнесенных преград высокоскоростными стержневыми ударниками с достаточно высокой 
Таблица 1. Параметры математической модели исследуемых материалов

\begin{tabular}{c|c|c|c|c|c|c|c|c|c|c|c}
\hline Материал & $\begin{array}{c}\rho_{0}, \\
\mathrm{~g} / \mathrm{cm}^{3}\end{array}$ & $\begin{array}{c}\rho_{m 0}, \\
\mathrm{~g} / \mathrm{cm}^{3}\end{array}$ & $\begin{array}{c}c_{m 0}, \\
\mathrm{~m} / \mathrm{s}\end{array}$ & $S_{m 0}$ & $\gamma_{m 0}$ & $\begin{array}{c}\mu_{m 0}, \\
\mathrm{GPa}\end{array}$ & $\begin{array}{c}\sigma_{m s}, \\
\mathrm{GPa}\end{array}$ & $\begin{array}{c}a_{s}, \\
\mathrm{GPa}\end{array}$ & $\alpha_{00}$ & $\xi^{*}$ & $\begin{array}{c}A_{*}^{p}, \\
\mathrm{GPa}\end{array}$ \\
\hline $\mathrm{TiB}_{2}+\mathrm{NiTi}$ & 4.92 & 5.12 & 690 & 2.2 & 1.5 & 128.27 & 0.75 & 0.5006 & 1.0006 & 0.1 & 0.5 \\
$\mathrm{BT} 1-0$ & 4.32 & 4.32 & 478 & 1.088 & 1.33 & 48.0 & 0.6 & 0.42 & 1.0001 & 0.3 & 0.1 \\
Сталь & 7.85 & 7.85 & 457 & 1.49 & 2.0 & 79.0 & 1.0 & 0.43 & 1.0006 & 0.3 & 0.3
\end{tabular}

точностью. А в [20] представлена численная трехмерная методика для моделирования ударного взаимодействия тупоносых снарядов из тяжелого вольфрамового сплава с плиткой из корундовой керамики. Также численные методы в механике сплошной среды для решения задач высокоскоростного деформирования и разрушения твердых тел в лагранжевом представлении реализованы в полной пространственной постанове [21], в эйлеровом представлении для двумерного случая - в [22].

Дальнейшая модернизация керамических материалов для достижения необходимой ударной стойкости возможна путем разработки многокомпонентных металлокерамических материалов с наличием эффективной связующей составляющей на металлической основе [23-26]. Повышенная адгезионная способность металлической матрицы и керамической составляющей может быть достигнута при получении металлокерамического материала методом самораспространяющегося высокотемпературного синтеза (СВС) с приложением давления к продукту синтеза [27]. При этом сочетание высоких температур (до $3000^{\circ} \mathrm{C}$ ) и повышенных давлений в контактных зонах межфазного взаимодействия в достаточной степени обеспечивают необходимые адгезионные свойства, что не всегда достигается традиционными способами спекания порошковых материалов.

Одним из перспективных методов повышения физикомеханических характеристик композиционных материалов для условий высокоскоростного соударения является получение металлокерамических материалов с переменным составом, в том числе слоистого типа, методом СВС с одновременным приложением давления к слоистой заготовке, содержащей экзотермическую порошковую смесь.

В работах $[28,29]$ представлен новый комбинированный металлокерамический материал на основе высокотвердой керамики в связке с интерметаллидом на высокопрочной металлической подложке - $\left(\mathrm{TiB}_{2}+\mathrm{NiTi}\right)+\mathrm{Ti}$, и проведено исследование его противоударной стойкости в сравнении с пластиной из титанового сплава ВТ1-0.

Целями настоящей работы являются дальнейшие расчетно-экспериментальные исследования поведения комбинированного металлокерамического материала $(\mathrm{KMM})\left(\mathrm{TiB}_{2}+\mathrm{NiTi}\right)+\mathrm{Ti}$ в сравнении с пластинами из титанового сплава, стали и корундовой керамики при соударении со сферическим стальным ударником в диапазоне скоростей порядка $2500 \mathrm{~m} / \mathrm{s}$.

Экспериментальные исследования защитных преград при высокоскоростном ударе проведены с применением экспериментального высокоскоростного баллистического стенда [30]. Математическое моделирование проведено в рамках пористой упругопластической среды с учетом различных механизмов разрушения материалов $[31,23]$, модифицированной для сред со сложным составом. Математическая модель реализована с помощью программного комплекса [22]. В табл. 1 приведены параметры математической модели исследуемых материалов, где обозначено: $\rho_{0}$ - начальная плотность материала; $\rho_{m 0}, c_{m 0}, S_{m 0}, \gamma_{m 0}, \mu_{m 0}, \sigma_{m s}$ - параметры матрицы материала; $a_{s}, \alpha_{00}, \alpha_{0}, \xi^{*}, A_{*}^{p}-$ параметры модели разрушения.

\section{1. Методика экспериментального исследования}

С целью определения баллистической стойкости пластины из КММ $\left(\mathrm{TiB}_{2}+\mathrm{NiTi}\right)+\mathrm{Ti}$ в сравнении с пластинами из сплава титана (BT1-0), стали (СТ-3) и корундовой керамики $\left(\mathrm{Al}_{2} \mathrm{O}_{3}\right)$ при высокоскоростном соударении проводятся баллистические испытания соударения пластин из данных материалов со стальным сферическим ударником. На рис. 1, $a$ приведена схема экспериментального баллистического стенда, представленного четырьмя секциями: участок разгона I на основе баллистической установки калибром $23 \mathrm{~mm}$ (I, 1, рис. 1, b), участок вакуумного глушителя (II, 3), участок отделения компонентов метаемой сборки (III, 5), который соединен с вакуумным глушителем мембраной 4, и мишенный участок (IV, 7 - преграда, 8 - преграда-,свидетель“) представлены на рис. 1, c.

Мишень состоит из образца испытуемого материала, расположенного на некотором расстоянии от преграды„свидетеля“ (IV, 7, 8). Роль преграды-„свидетеля“ состоит в улавливании осколочного потока после взаимодействия ударника с испытуемым образцом. На участке отделения и на мишенном участке предусмотрены иллюминаторы $(\mathrm{IV}, 6)$, позволяющие наблюдать за происходящими на траектории процессами с помощью высокоскоростных видеорегистраторов.

Для обеспечения приемлемого качества обтюрации в стволе баллистической установки ударник помещается в ведущее устройство (рис. $1, d$ ). Метаемая сборка состоит из поддона, металлической пластины - метки для регистрации скорости и сферического ударника. Так как компоненты ведущего устройства способны повредить мишень и повлиять на конечный результат, их не 

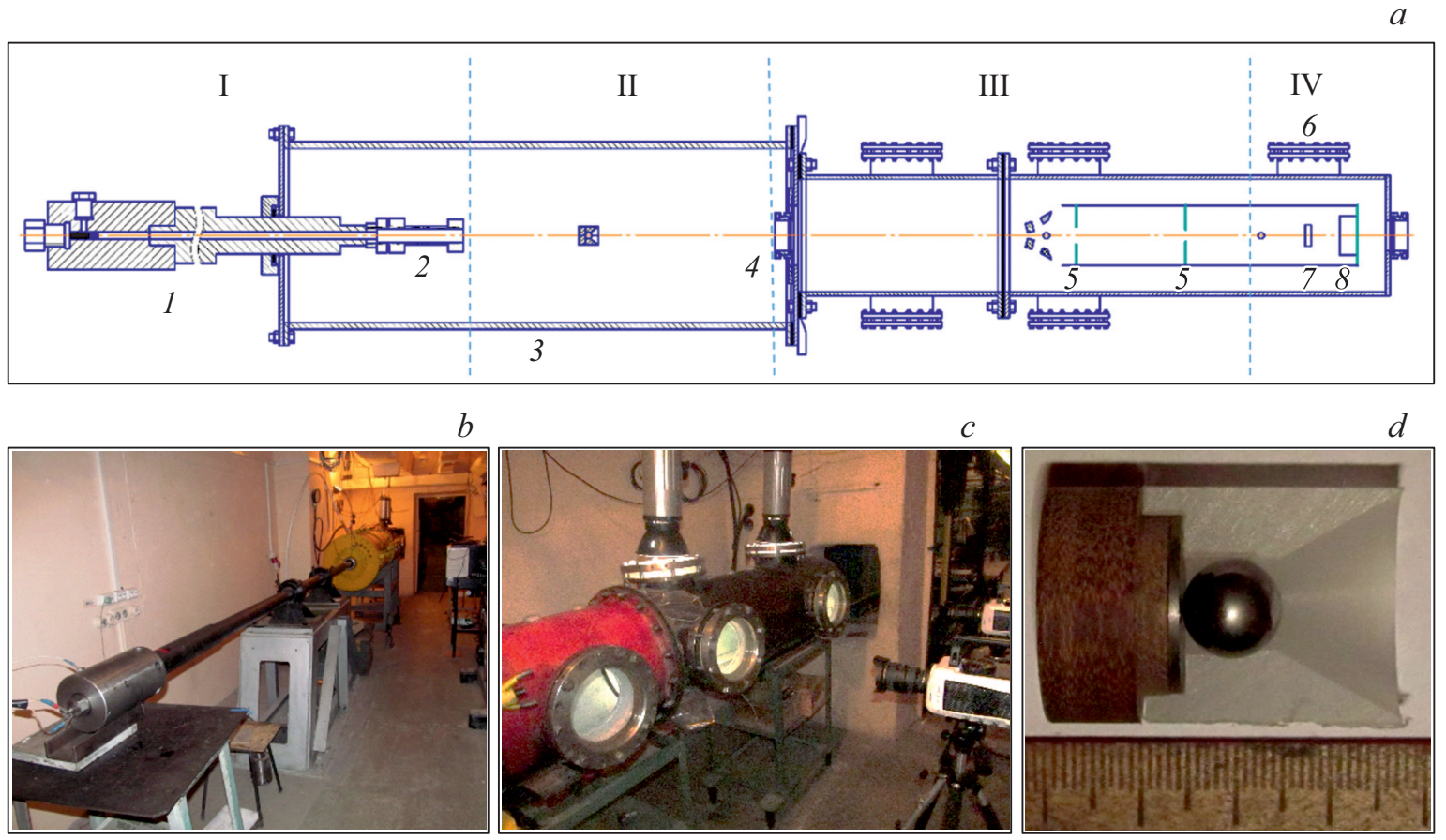

Рис. 1. Вид баллистического стенда: $a-$ схема стенда, $b-$ баллистическая установка, $c-$ участок отделения и мишенный участок, $d$ - метаемая сборка.

скрепляют между собой. Попадая из вакуумного глушителя в атмосферу, компоненты сборки разделяются под действием аэродинамических сил и попадают в отсекатели (III, 5), представляющие собой две разнесенные на $0.5 \mathrm{~m}$ стальные пластины с отверстиями 25 и $30 \mathrm{~mm}$ соосно траектории движения ударника. Таким образом, при наличии соответствующей методики прицеливания и точности юстировки компонентов стенда достигается стабильное освобождение метаемого ударника от нежелательных фрагментов, сопутствующих применяемой технологии метания.

Регистрация скорости движения ударника происходит на выходе из ствола с помощью индукционного датчика дульной скорости [32] $(\mathrm{I}, 2)$, а также на траектории до момента контакта с целью $V_{0}$ и после взаимодействия $V_{c}$ по кадрам видеорегистрации процесса соударения. Видеорегистрация во всех опытах производилась с частотой $71 \mathrm{kHz}$.

Для оценки характерных скоростей взаимодействия с целью минимизации влияния оптической перспективы, аберрации оптической системы видеорегистратора и наглядности получаемого результата в области съемки на 15-20 mm ниже оси метания и строго под ней устанавливается эталонная линейка, по которой производится оценка характерных масштабов и перемещений в наблюдаемой плоскости взаимодействия. Инструментальная погрешность оптической системы видеорегистратора в используемой в серии опытов конфигурации составила $0.25 \mathrm{~mm}$, что вкупе с абсолютной погрешностью измерения межкадрового периода $( \pm 20 \mathrm{~ns})$ и операторной погрешностью, зависящей от условий съемки, позволяет объективно производить оценку относительного перемещения ударника между кадрами с абсолютной погрешностью $\pm 0.5 \mathrm{~mm}$. В зависимости от количества доступных для обработки кадров и проходимого ударником расстояния между кадрами относительная погрешность оценки скорости ударника может меняться, но не превышает $1.5 \%$.

\section{2. Свойства комбинированного металлокерамического материала $\left(\mathrm{TiB}_{2}+\mathrm{NiTi}\right)+\mathrm{Ti}$}

Методом СВС с приложением давления к продукту синтеза разработан КММ для защитных преград от высокоскоростного удара $\left(\mathrm{TiB}_{2}+\mathrm{NiTi}\right)+\mathrm{Ti}$ [28]. Образец

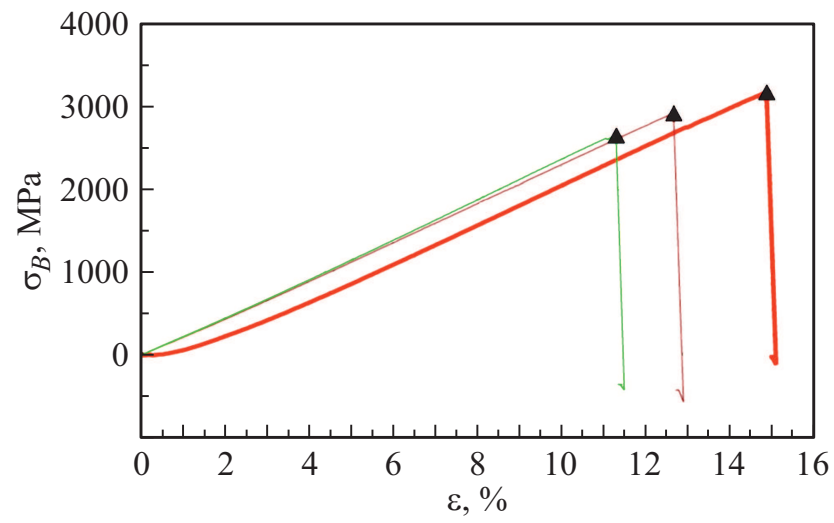

Рис. 2. Диаграмма нагружения металлокерамического материала $\mathrm{TiB}_{2}+\mathrm{NiTi}$ при сжатии. 
a
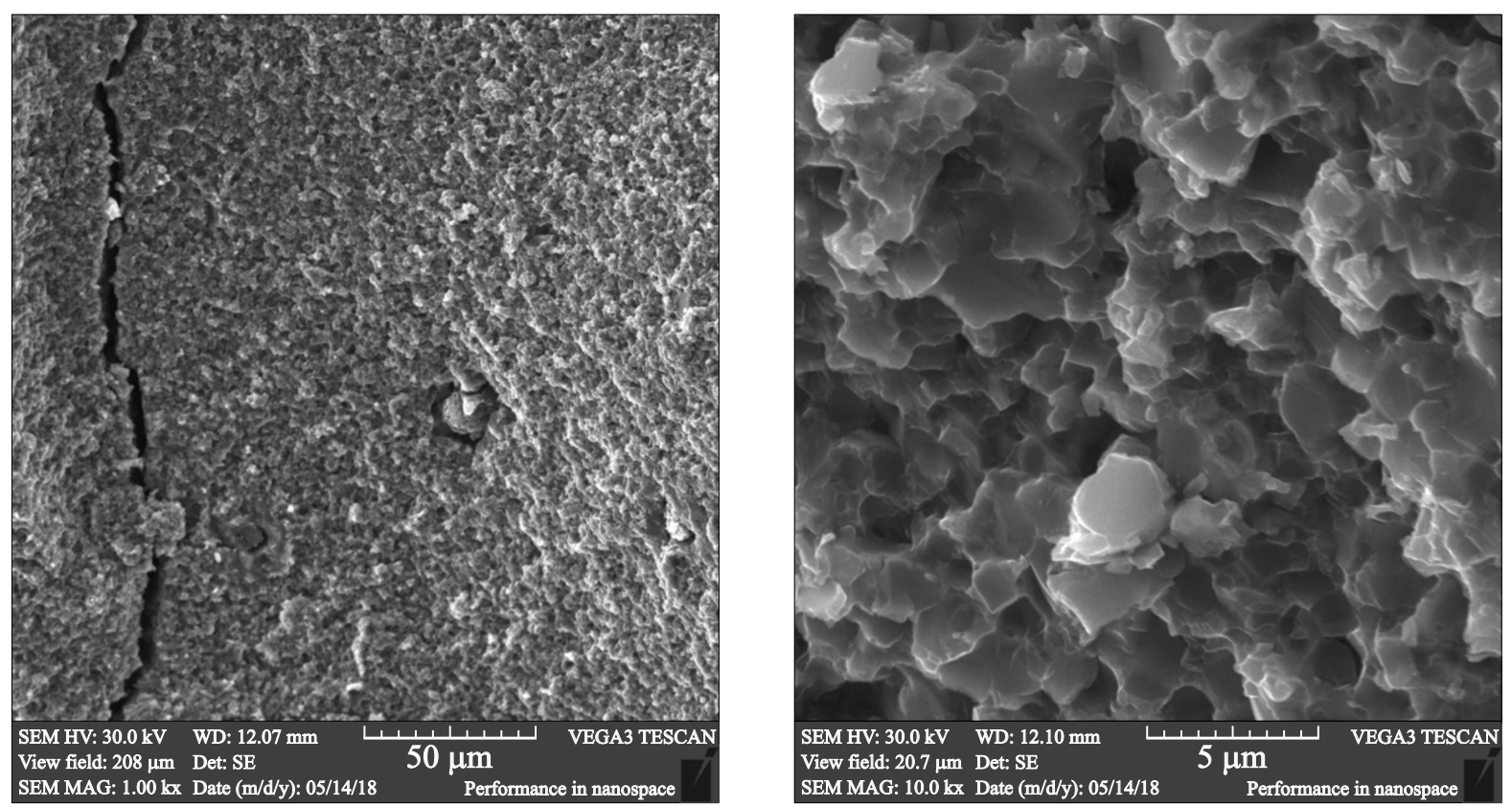

Рис. 3. Поверхности разрушения металлокерамического материала $\mathrm{TiB}_{2}+\mathrm{NiTi}$ при различном увеличении.
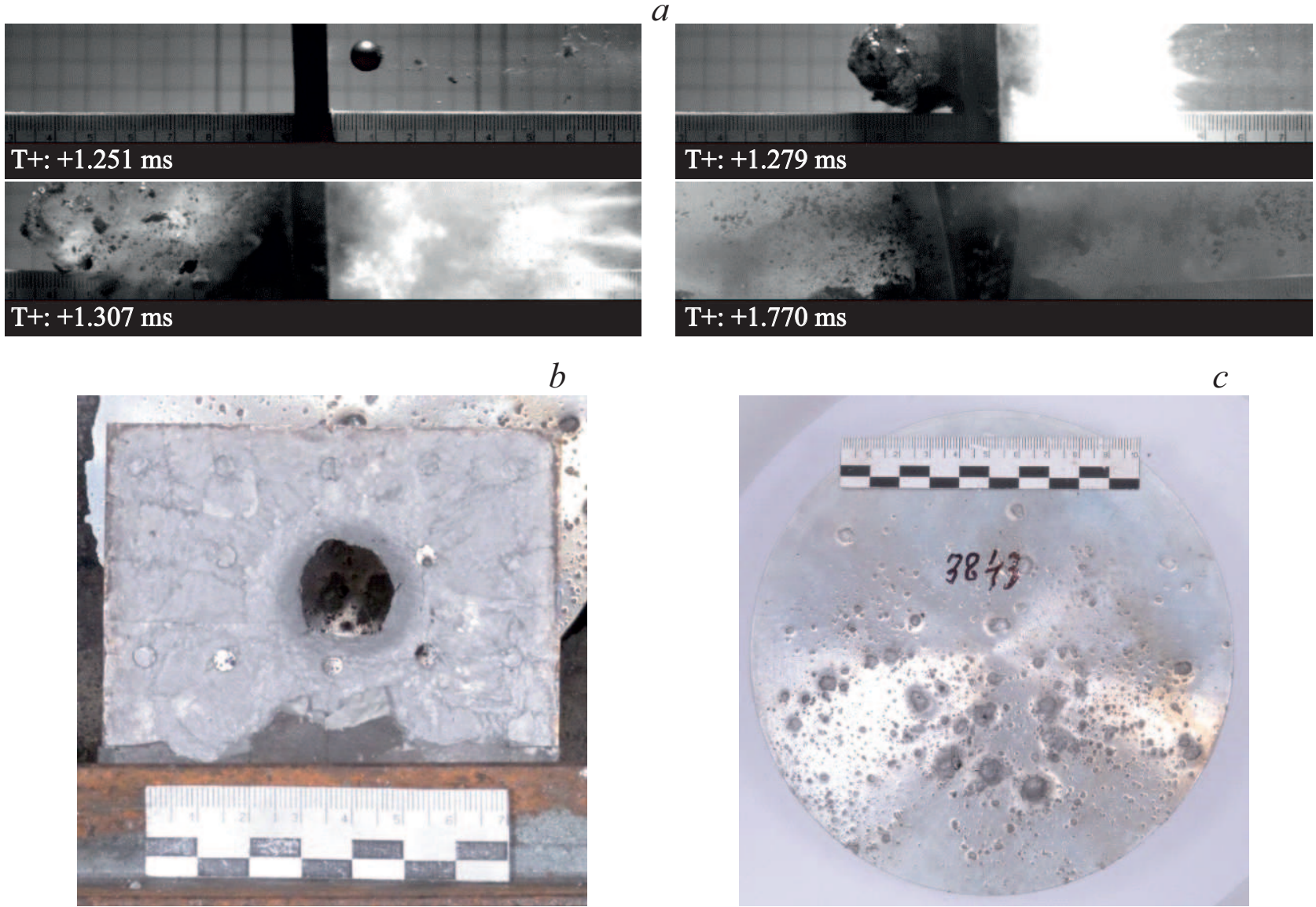

Рис. 4. Фоторегистограмма пробития образцом комбинированного металлокерамического материала $(\mathrm{TiB} 2+\mathrm{NiTi})+\mathrm{Ti}(a)$, вид остатка образца $\left(\mathrm{TiB}_{2}+\mathrm{NiTi}\right)+\mathrm{Ti}(b)$ и лицевой поверхности „свидетеля“ $(c)$ после соударения при $V_{0}=2395 \mathrm{~m} / \mathrm{s}$. 

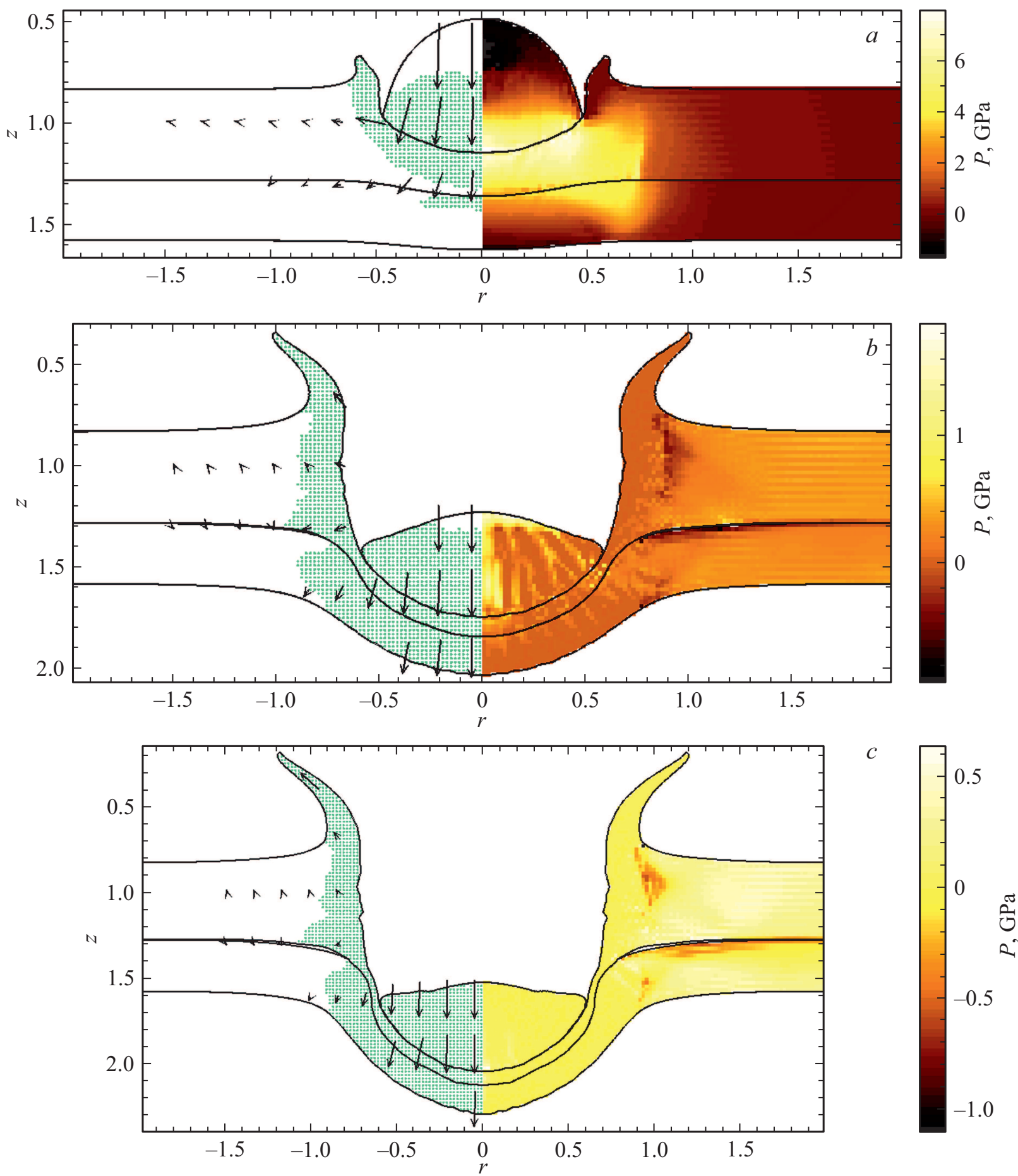

Рис. 5. Хронограмма взаимодействия стального сферического ударника с образцом комбинированного металлокерамического материала $\left(\mathrm{TiB}_{2}+\mathrm{NiTi}\right)+\mathrm{Ti}$ при $V_{0}=2395 \mathrm{~m} / \mathrm{s}: a-t=2 \mu \mathrm{s}, U_{\max }=2169 \mathrm{~m} / \mathrm{s}, U_{\mathrm{cm}}=1825 \mathrm{~m} / \mathrm{s}, P_{\min }=-1.73 \mathrm{GPa}, P_{\max }=7.91 \mathrm{GPa}$; $b-t=6 \mu \mathrm{s}, U_{\max }=1559 \mathrm{~m} / \mathrm{s}, U_{\mathrm{cm}}=1405 \mathrm{~m} / \mathrm{s}, P_{\min }=-0.95 \mathrm{GPa}, P_{\max }=1.87 \mathrm{GPa} ; c-t=8 \mu \mathrm{s}, U_{\max }=1499 \mathrm{~m} / \mathrm{s}, U_{\mathrm{cm}}=1371 \mathrm{~m} / \mathrm{s}$, $P_{\min }=-1.09 \mathrm{GPa}, P_{\max }=0.63 \mathrm{GPa}$.

КММ $\left(\mathrm{TiB}_{2}+\mathrm{NiTi}\right)+\mathrm{Ti}$ состоит из двух слоев: лицевой слой толщиной $4.5 \mathrm{~mm}$ представлен интерметаллидом $\mathrm{TiB}_{2}+\mathrm{NiTi}$ (металлокерамика) плотностью $4.92 \mathrm{~g} / \mathrm{cm}^{3}$, тыльный слой толщиной $3 \mathrm{~mm}$ - сплав титана ВТ1-0 плотностью $4.32 \mathrm{~g} / \mathrm{cm}^{3}$. Средняя плотность образца KMM $\left(\mathrm{TiB}_{2}+\mathrm{NiTi}\right)+\mathrm{Ti}$ составляет $4.68 \mathrm{~g} / \mathrm{cm}^{3}$.
Микроструктура лицевого слоя КММ TiB $2+\mathrm{NiTi}$ представляет собой смесь мелкокристаллических частиц $\mathrm{TiB}_{2}$ размером до $5 \mu \mathrm{m}$ и равномерно распределенной связующей фазы NiTi, микротвердость лицевого слоя, т.е. частиц $\mathrm{TiB}_{2}$ и связующей матрицы NiTi, составляет от 7.5 до $26 \mathrm{GPa}$, предел прочности на изгиб 


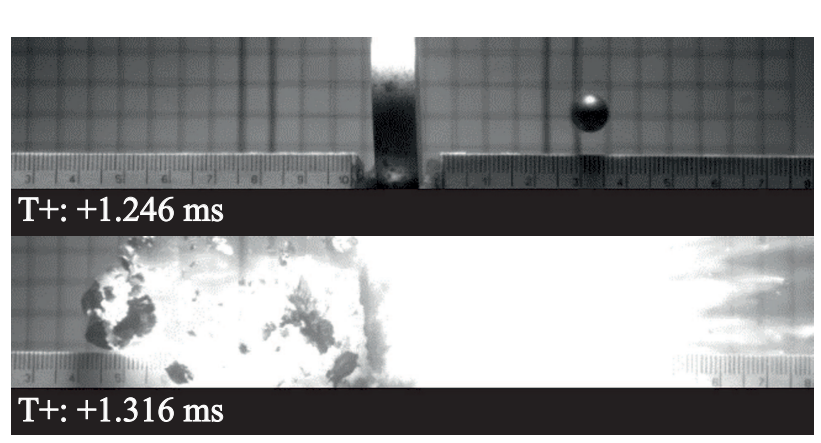

$b$

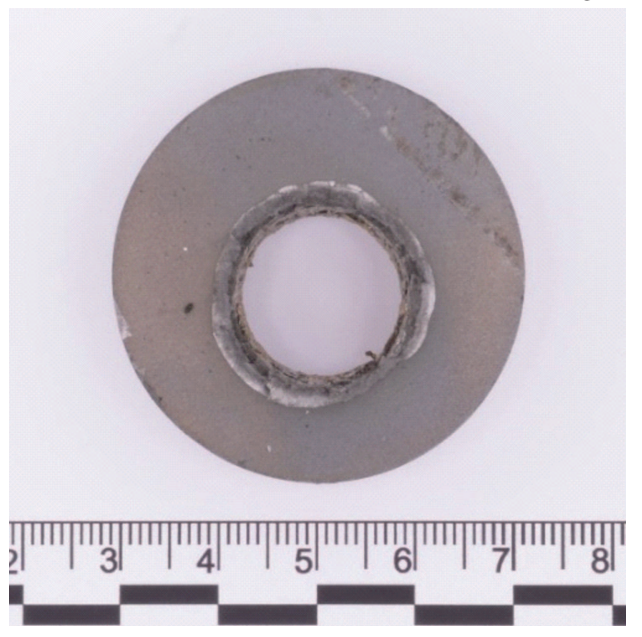

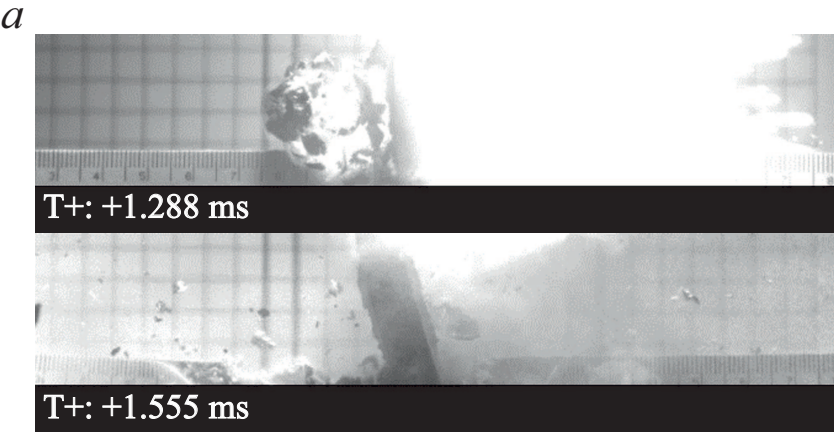

C

Рис. 6. Фоторегистограмма пробития титановой пластины $(a)$, вид титановой пластины $(b)$ и лицевой поверхности „свидетеля“ после соударения $(c)$ при $V_{0}=2433 \mathrm{~m} / \mathrm{s}$.

Таблица 2. Результаты баллистических испытаний

\begin{tabular}{c|c|c|c|c|c|c|c}
\hline $\begin{array}{c}\text { Образец } \\
\text { материала }\end{array}$ & $\begin{array}{c}\rho_{\text {sam }}, \\
\mathrm{g} / \mathrm{cm}^{3}\end{array}$ & $\begin{array}{c}h_{\text {sam }}, \\
\mathrm{mm}\end{array}$ & $\begin{array}{c}\rho_{\text {sam }}, \\
h_{\text {sam }}, \mathrm{g} / \mathrm{cm}^{2}\end{array}$ & $\begin{array}{c}V_{0}, \\
\mathrm{~m} / \mathrm{s}\end{array}$ & $\begin{array}{c}V_{c}, \\
\mathrm{~m} / \mathrm{s}\end{array}$ & $\begin{array}{c}h_{c}, \\
\mathrm{~mm}\end{array}$ & $\varphi,^{\circ}$ \\
\hline$\left(\mathrm{TiB}_{2}+\mathrm{NiTi}\right)+\mathrm{Ti}$ & 4.68 & 7.5 & 3.51 & 2395 & 1405 & 5.5 & 35.4 \\
$\mathrm{BT} 1-0$ & 4.32 & 9.0 & 3.89 & 2433 & 1204 & 7.3 & 31.81 \\
$\mathrm{CT}-3$ & 7.85 & 4.8 & 3.77 & 2413 & 1403 & 8.6 & 24.91 \\
$\mathrm{Al}_{2} \mathrm{O}_{3}$ & 3.67 & 9.8 & 3.60 & 2443 & 1145 & 6.4 & 29.88
\end{tabular}

KMM $\left(\mathrm{TiB}_{2}+\mathrm{NiTi}\right)+\mathrm{Ti}$ (при боковой нагрузке) составляет $365 \mathrm{MPa}$, как показано в [28].

Испытания на сжатие лицевого металлокерамического слоя $\mathrm{TiB}_{2}+\mathrm{NiTi}$ проведены на электромеханической машине Instron 3369 при скорости нагружения $0.2 \mathrm{~mm} / \mathrm{min}$. Для этой цели из синтезированного металлокерамического слоя вырезаны три цилиндрических образца диаметром $3 \mathrm{~mm}$ и высотой $4 \mathrm{~mm}$ каждый. На рис. 2 представлены диаграммы нагружения данных образцов. Наблюдаемый небольшой разброс связан с особенностями распределения компонентов в объеме металлокерамического слоя. Среднее значение предела прочности $\sigma_{\text {в }}$ и относительной деформации $\varepsilon$ составляют $2916 \mathrm{MPa}$ и $13 \%$ соответственно.
С использованием растровой электронной микроскопии получена структура поверхностей разрушения данного материала, которые представлены на рис. 3. Отчетливо видно, что имеет место межзеренное хрупкое разрушение с развитием характерных трещин, края которых повторяют контур межкристаллитных границ.

Отличительной особенностью $\mathrm{TiB}_{2}+\mathrm{NiTi}$ является повышенная трещиностойкость по сравнению с однофазными высокопрочными керамиками типа карбида бора, карбида кремния или оксида алюминия. Введение металлической связки делает материал более пластичным, вязким, препятствует росту трещин при сжатии и особенно растяжении, когда разрушение идет в основном по границам зерен. Вместе с тем уровень пластичности металлокерамики в целом незначителен и составляет несколько процентов.

Как показано в [29], по результатам анализа соударения стального сферического ударника с образцом КММ $\left(\mathrm{TiB}_{2}+\mathrm{NiTi}\right)+\mathrm{Ti}$ при скорости удара $500 \mathrm{~m} / \mathrm{s}$ в сравнении с эквивалентной однородной титановой пластиной, вопервых, наблюдается качественное различие в характере взаимодействия, выражающееся в отсутствии ударного кратера в металлокерамическом слое после соударения; во-вторых, КММ оказывает большое сопротивление прониканию стального ударника. Тыльный слой из тита- 


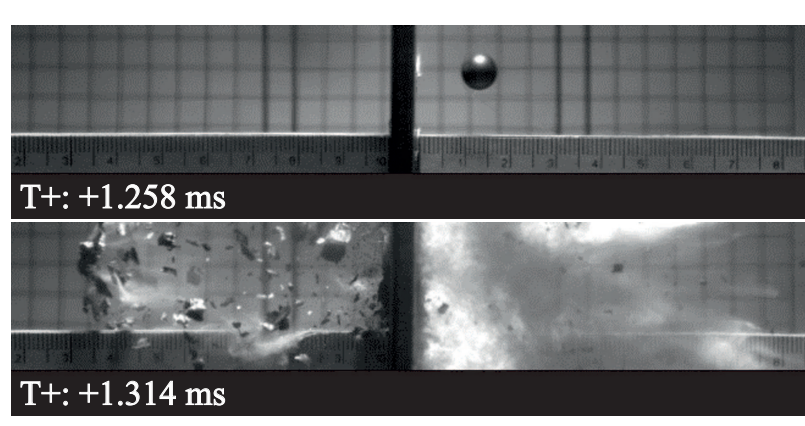

$b$

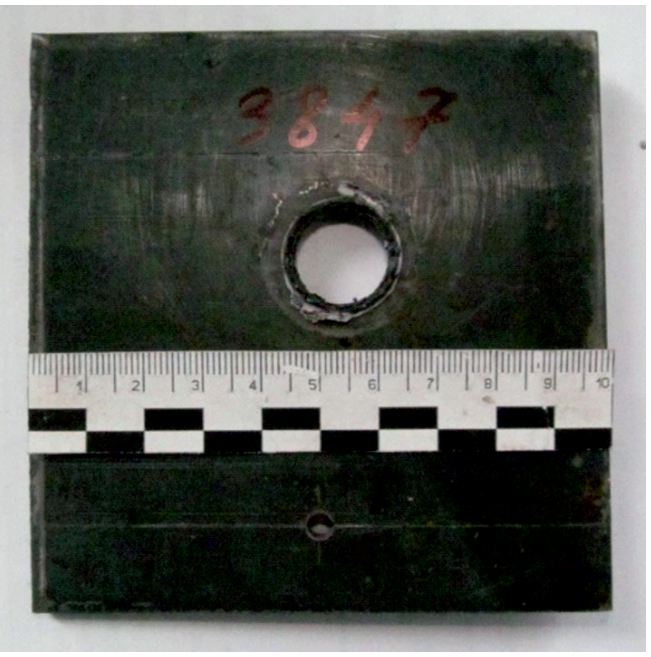

$a$

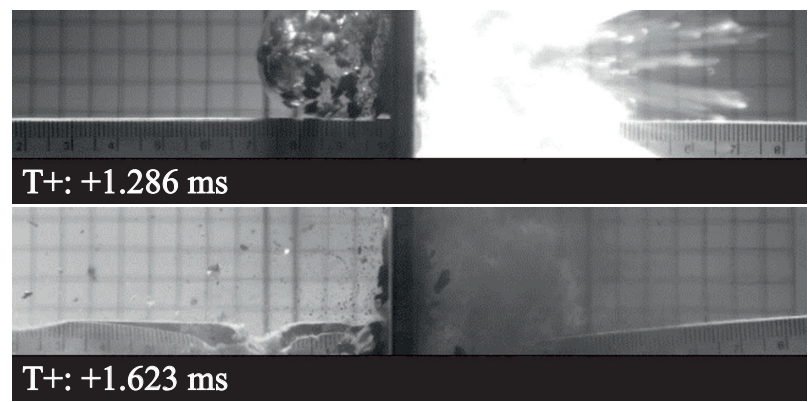

$c$

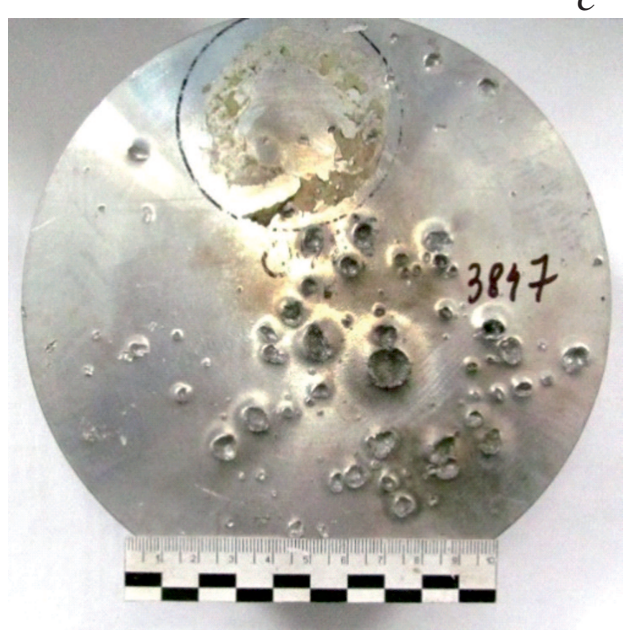

Рис. 7. Фоторегистограмма пробития $(a)$, вид стальной пластины $(b)$ и лицевой поверхности „свидетеля“ $(c)$ после соударения при $V_{0}=2413 \mathrm{~m} / \mathrm{s}$.

нового сплава демпфирует ударную нагрузку, приходящуюся на металлокерамический слой при соударении.

\section{3. Результаты экспериментально-теоретических исследований}

Для исследования баллистической стойкости образцов КММ $\left(\mathrm{TiB}_{2}+\mathrm{NiTi}\right)+\mathrm{Ti}$ в сравнении с пластинами из титанового сплава ВТ1-0, стали и корундовой керамики $\mathrm{Al}_{2} \mathrm{O}_{3}$ проведена серии экспериментов при скорости удара порядка $2500 \mathrm{~m} / \mathrm{s}$. Ударник представляет собой шар диаметром $10 \mathrm{~mm}$ из термоупрочненной стали ШХ-15 твердостью 70 HRC. Ударник взаимодействует с образцом испытуемого материала, расположенным на некотором расстоянии $H \sim 214 \mathrm{~mm}$ от массивной преграды„свидетеля“, в качестве которого используется диск из сплава алюминия Д16Т, диаметром $155 \mathrm{~mm}$, толщиной $70 \mathrm{~mm}$. По результатам видеосьемки определились значения скорости ударника $V_{0}$ до и скорости лидирующего осколка $V_{c}$ после взаимодействия с преградой, а также измерялась глубина кратера $h_{c}$ в „свидетеле“ от удара лидирующим осколком и телесный угол разлета осколков $\varphi$.
В табл. 2 приведены характеристики испытуемых образцов: плотность $\rho_{\text {sam }}$, толщина $h_{\text {sam }}$, поверхностная плотность $\rho_{\text {sam }} \cdot h_{\text {sam }}$ и результаты опытов.

На рис. 4 запечатлен процесс пробития стальным сферическим ударником образца КММ $\left(\mathrm{TiB}_{2}+\mathrm{NiTi}\right)+\mathrm{Ti}$ при $V_{0}=2395 \mathrm{~m} / \mathrm{s}$. На первой стадии процесса наблюдается пробитие преграды и выброс материала как с тыльной стороны в виде осколочного потока, так и из зоны кратера на лицевой поверхности. При $t=1.275 \mu \mathrm{s}$ наблюдается отклонение тыльной титановой части пластины по направлению удара, а лицевая часть металлокерамики претерпевает разрушение. В запреградном пространстве распространяется поле осколков, состоящее из фрагментов преграды и ударника. Лицевая поверхность преграды-,свидетеля“ испещрена этими осколками (рис. 4,c). В результате соударения телесный угол разлета осколков в запреградном потоке составляет $\varphi=35.4^{\circ}$, скорость лидирующего осколка $V_{c}=1405 \mathrm{~m} / \mathrm{s}$, глубина каверны от лидирующего осколка $h_{c}=5.5 \mathrm{~mm}$.

Начальная стадия процесса моделируется в вычислительном эксперименте аналогично [29], иллюстрируемом на рис. 5. Результаты расчета приведены в цилиндрической системе координат $r, z$ : в левой полуплоскости в виде распределения векторов массовой скорости 


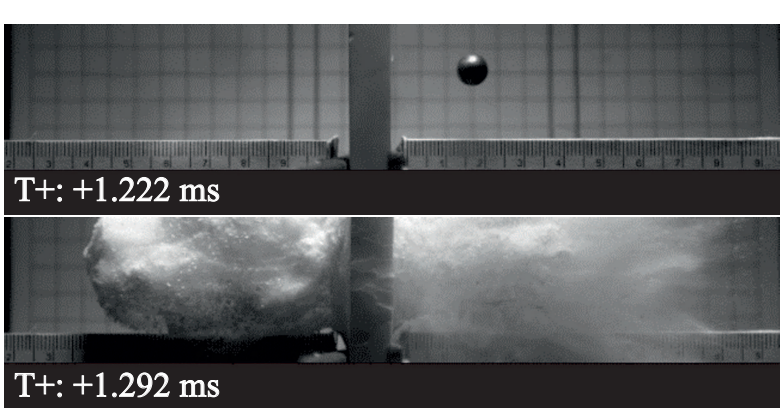

$b$

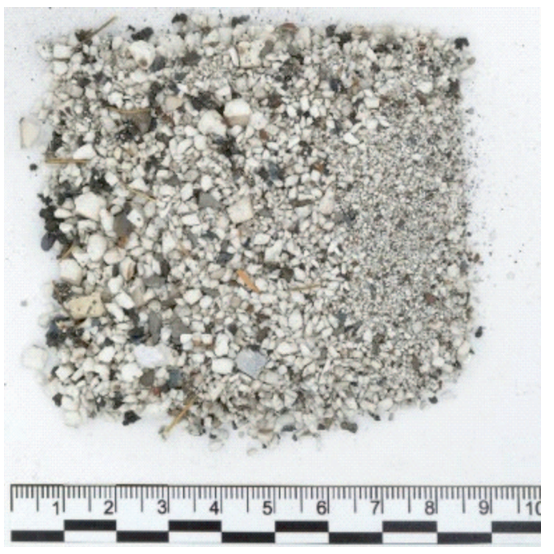

$a$

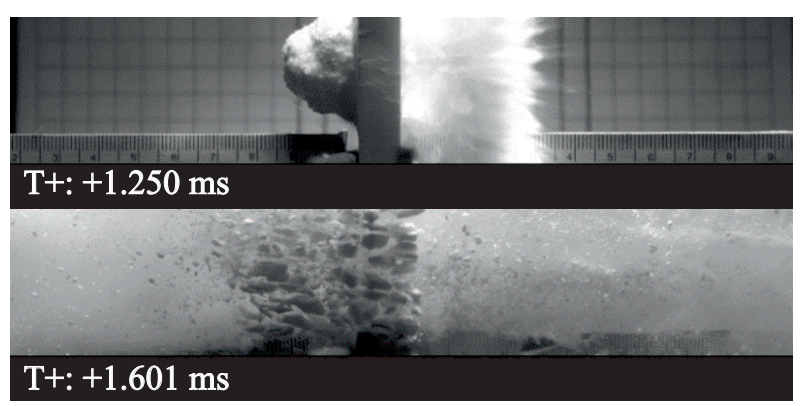

C

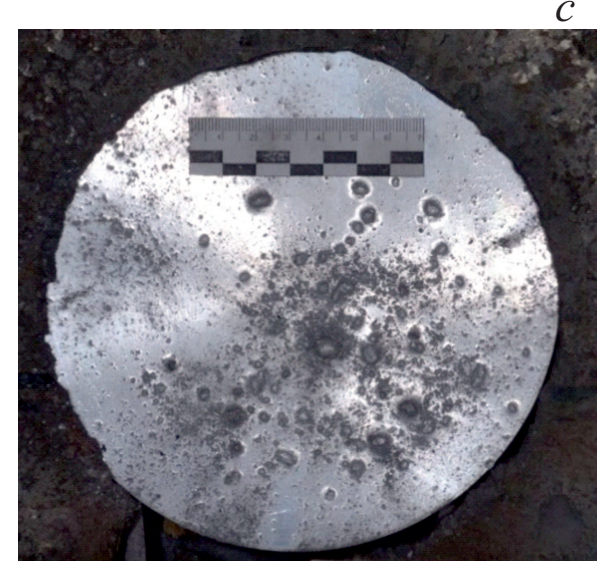

Рис. 8. Фоторегистограмма пробития $(a)$, вид фрагментов пластины из $\mathrm{Al}_{2} \mathrm{O}_{3}(b)$ и лицевой поверхности „свидетеля“ $(c)$ после соударения при $V_{0}=2443 \mathrm{~m} / \mathrm{s}$.

относительно максимального значения $U_{\max }$, в правой полуплоскости в виде распределения давления. Приведены также максимальное $P_{\max }$ и минимальное $P_{\min }$ значения давления и скорость центра масс ударника $U_{\mathrm{cm}}$. Расчет проведен до момента времени, когда величина вектора скорости $U_{\mathrm{cm}}$ практически не изменяется. Материал ударника и слои преграды в зоне контакта разрушаются. Скорость ударника после пробития преграды в расчете - $1371 \mathrm{~m} / \mathrm{s}$, относительная погрешность с экспериментом - 2.4\%. При $t=2 \mu$ s ударная волна, образовавшаяся при ударе в отличие от первой серии опытов, достигнув тыльной стороны преграды, отражается волной разгрузки, что приводит к разрушению и разлету материала преграды с тыльной поверхности. В ударнике зона разрушения распространяется от зоны контакта к тылу. На более поздней стадии процесса наблюдается расширяющееся поле осколков с тыльной стороны (рис. 5,c) и отслоение металлокерамического слоя $\mathrm{TiB}_{2}+\mathrm{NiTi}$ от титановой подложки при $t=8 \mu \mathrm{s}$. Преграда-,свидетель“ улавливает фрагменты осколочного потока. Лидирующий осколок оставляет кратер глубиной $h_{c}=5.5 \mathrm{~mm}$.

На рис. 6,7 и 8 проиллюстрированы результаты взаимодействия ударника с пластинами титана, стали и керамики.

Во всех рассмотренных случаях говорить о баллистической стойкости преград в исследуемом диапазоне скоростей порядка $2400 \mathrm{~m} / \mathrm{s}$ не приходится: все преграды пробиты стальным сферическим ударником. Во всех случаях наблюдается разлет осколков в запреградном пространстве и взаимодействие их с преградой„свидетелем“. Преграда из керамики $\mathrm{Al}_{2} \mathrm{O}_{3}$ полностью разрушена. Остальные образцы при наличии пробоины сохраняют несущую способность после соударения.

Исходя из анализа результатов, представленных в табл. 2, образец КММ $\left(\mathrm{TiB}_{2}+\mathrm{NiTi}\right)+\mathrm{Ti}$, несмотря на меньшую поверхностную плотность, оказывает большее воздействие на ударник при соударении. И хотя скорость осколка после пробития металлокерамики самая высокая, глубина каверны в „свидетеле“ от него наименьшая. Это важный результат, указывающий на то, что ударник претерпевает более сильное фрагментирование, чем при соударении с металлическими и керамическими пластинами, что видно также по наибольшему углу разлета осколков $\varphi=35.4^{\circ}$, и запреградное действие осколков является более рассредоточенным.

\section{Заключение}

Выполнены расчетно-экспериментальные исследования поведения КММ ( $\left.\mathrm{TiB}_{2}+\mathrm{NiTi}\right)+\mathrm{Ti}$ при высокоскоростном соударении со сферическим стальным ударником. Полученные результаты сопоставлены с данными 
аналогичных исследований пластин из титанового сплава, стали и корундовой керамики.

При соударении пластин из исследуемых материалов со сферическим стальным ударником при скоростях порядка $2400 \mathrm{~m} / \mathrm{s}$ все преграды пробиты, а ударник разрушен. Пластины, кроме корундовой керамики, сохраняют свою несущую способность после соударения.

Пластина КММ $\left(\mathrm{TiB}_{2}+\mathrm{NiTi}\right)+\mathrm{Ti}$ оказывает большее силовое воздействие на ударник, чем титан и сталь, что выражается в более интенсивном фрагментировании ударника и, как следствие, запреградное действие осколков является более рассредоточенным.

\section{Благодарности}

В работе использованы результаты, полученные в ходе выполнения проекта № 8.2.09.2018 Программы повышения конкурентоспособности Национального исследовательского Томского государственного университета.

\section{Конфликт интересов}

Авторы заявляют, что у них нет конфликта интересов.

\section{Список литературы}

[1] Jianfeng Liu, Yuan Long, Chong Ji, Qiang Liu, Mingshou Zhong, You Zhou // Intern. J. Impact Engin. 2018. Vol. 112. P. 52-65.

[2] Deng Yunfei, Zhang Wei, Yang Yonggang, Shi Lizhong, Wei Gang // Int. J. Impact Engin. 2014. Vol. 70. P. 38-49.

[3] Deng Yunfei, Zhang Wei, Qing Guanghui, Wei Gang, Yang Yonggang, Hao Peng // Materials \& Design. 1980 2015. 2014. Vol. 54. P. 1056-1067.

[4] Yunfei Deng, Wei Zhang, Zongsheng Cao // Materials \& Design. 2013. Vol. 44. P. 228-239.

[5] Хорев И.Е., Толкачев В.Ф., Ерохин Г.А. // Космические исследования. 2007. Т. 45. № 2. С. 183-188. [Khorev I.E., Tolkachev V.F., Erokhin G.A. // Cosmic Research. 2007. Vol. 45. N 2. P. 170-175.]

[6] Захаров В.М., Табаченко А.Н., Абанасьева С.А. // ЖТФ. 2017. Т. 87. Вып. 7. С. $1003-1007$. DOI: $10.1134 / \mathrm{S} 1063784217070283$

[Zakharov V.M., Tabachenko A.N., Afanas'eva S.A. // Tech. Phys. 2017. T. 62. N 7. P. 1019-1023.]

[7] Дударев Е.Ф., Грабовеикая Г.П., Колобов Ю.Р., Бакач Г.П., Кашин О.А., Жу Ю.Т. // Металлы. 2004. N 1. C. 87-95. [Dudarev E.F., Bakach G.P., Grabovetskaya G.P., Kolobov Yu.R., Kashin O.A., Zhu Yu.T. Rus. Metall. (Metally). 2004. N 1. P. 75-82.]

[8] Ищенко А.Н., Абанасьева С.А., Буркин В.В., Дударев Е.Ф., Рогаев К.С., Табаченко А.Н., Хабибуллин М.В // Космические исследования. 2016. Т. 54. № 6. С. 479-485. [Ishchenko A.N., Afanas'eva S.A., Burkin V.V., Dudarev E.F., Rogaev K.S., Tabachenko A.N., Khabibullin M.V. // Cosmic Resear. 2016. Vol. 54. N 6. P. 438-444.

[9] Канель Г.И., Разоренов С.В., Уткин А.В., Фортов В.Е. Ударно-волновые явления в конденсированных средах. М.: Янус-К, 1996. 408 с.
[10] Толкачев В.Ф. // В сб.: Естественные и математические науки: вопросы и тенденции развития. Сборник научных трудов по итогам международной научно-практической конференции. 2016. С. 11-15.

[11] Minhyung Lee, Sangwon Park, Ilguk Jo, Sangkwan Lee // Proced. Engin. 2017. Vol. 204. P. 100-107.

[12] Runqiang Chi, Ahmad Serjouei, Idapalapati Sridhar, Geoffrey E.B. Tan // Intern. J. Impact Engine. 2013. Vol. 52. P. 37-46.

[13] Pawar M.J., Patnaik A., Biswas S.K., Pandel U., Bhat I.K., Chatterjee S., Mukhopadhyay A.K., Banerjee R., Babu B.P. // Int. J. Impact Engine. 2016. Vol. 98. P. 42-51.

[14] Kemal Arslan, Recep Gunes // Compos. Structur. 2018. В печати. ISSN 0263-8223. https://doi.org/10.1016/j.compstruct.2018.01.087

[15] Кобылкин И.Ф., Селиванов В.В. Материалы и структуры легкой бронезащиты. М.: Изд-во МГТУ им. Н.Э. Баумана, 2014. $191 \mathrm{c}$.

[16] Кобылкин И.Ф., Горбатенко А.А. // Вестн. МГТУ им. Н.Э. Баумана. Серия: Машиностроение. 2018. № 2 (119). C. $17-30$.

[17] Кобылкин И.Ф. // Физика горения и взрыва. 2017. Т. 53. № 4. C. 126-133. [Kobylkin I.F. Combustion, Explosion, and Shock Waves. 2017. Vol. 53. N 4. P. 483-489.]

[18] Rajan S.D. // In Woodhead Publishing Series in Composites Science and Engineering, Lightweight Ballistic Composites (Second Edition), Woodhead Publishing, 2016. P. 327-348.

[19] Герасимов А.B. // Изв. Томского политех. ун-та. Инжиниринг георесурсов. 2015. Т. 326. № 1. С. 139-145.

[20] Bresciani L.M., Manes A., Romano T.A., Iavarone P. Giglio M. // Intern. J. Impact Engin. 2016. Vol. 87. P. 3-13.

[21] Югов Н.Т., Белов Н.Н., Югов А.А. Расчет адиабатических нестандартных течений в трехмерной постановке (РАНЕТ-3). Свидетельство о государственной регистрации программ для ЭВМ № 2010611042. Москва, 2010. Федеральная служба по интеллектуальной собственности, патентам и товарным знакам.

[22] Хабибуллин М.В., АЯбанасьева С.А. Расчет явлений, происходящих в конденсированных средах в результате интенсивных импульсных воздействий, в осесимметричной постановке. Федеральная служба по интеллектуальной собственности. Свидетельство о государственной регистрации программ для ЭВМ № 2012617301. М., 2012. $80 \mathrm{c}$.

[23] Белов Н.Н., Югов Н.Т., Афанасьева С.А., Табаченко А.Н., Коняев А.А., Толкачев В.Ф., Югов А.А. // ДАН. 2005. Т. 402. № 5. C. 617-622. [Belov N.N., Yugov N.T., Afanas'Eva S.A., Tabachenko A.N., Konyaev A.A., Tolkachev V.F., Yugov A.A. // Doklady Physics. 2005. Vol. 50. N 6. P. 315-319.]

[24] Белов Н.Н., Югов Н.Т., Табаченко А.Н., Афанасьева С.А., Югов А.А., Архипов И.Н., Мариунова Л.С. // Изв. вузов. Физика. 2008. Т. 51. № 7. С. 12-19. [Belov N.N., Yugov N.T., Tabachenko A.N., Afanas'eva S.A., Yugov A.A., Arkhipov I.N., Martsunova L.S. // Rus. Phys. J. 2008. Vol. 51. N 7. P. 671679.]

[25] Табаченко А.Н., Крючкова Г.Г. // ИФЖ НАН Беларуси. 1993. T. 65. № 4. C. 492-495.

[26] Табаченко А.Н., Мариунова Л.А., Скосырский А.Б., Белов Н.Н., Югов Н.Т., Афанасьева С.А. // Теоретические основы химической технологии. 2010. Т. 44. № 5. С. 582 587. [Tabachenko A.N., Martsunova L.A., Skosyrskii A.B., Belov N.N., Yugov N.T., Afanas'eva S.A. // Theor. Foundat. Chem. Engineer. 2010. Vol. 44. N 5. P. 723-728.] 
[27] Мержсанов А.Г. Физическая химия. Современные проблемы. М.: Химия, 1983. С. 6-45.

[28] Буркин В.В., Табаченко А.Н., Афанасьева С.А., Ищенко А.Н., Саммель А.Ю., Скосырский А.Б., Чупашев А.В. // Письма в ЖТФ. 2018. Т. 44. Вып. 8. С. $63-$ 69. DOI: 10.21883/PJTF.2018.08.45968.16945 [Burkin V.V., Tabachenko A.N., Afanas'eva S.A., Ishchenko A.N., Sammel' A.Yu., Skosyrskii A.B., Chupashev A.V. // Tech. Phys. Lett. 2018. Vol. 44. N 4. P. 344-347.

[29] Ищенко А.Н., Табаченко А.Н., Акиншин Р.Н., Абанасьева С.А., Белов Н.Н., Борисенков И.Л., Буркин В.В., Скосырский А.Б., Хабибуллин М.В., Чупашев А.В., Югов Н.Т. // ЖТФ. 2018. Т. 88. Вып. 7. С. 1018-1024. DOI: 10.21883/JTF.2018.07.46170.2556

[30] Бураков В.А., Буркин В.В., Ищенко А.Н., Корольков Л.В., Степанов Е.Ю., Чупашев А.В., Агафонов С.В., Рогаев К.С. / Патент на изобретение № 2591132 от 20 июня 2016 г.

[31] Белов Н.Н., Демидов В.Н., Ефремова Л.В., Жуков А.В., Николаев А.П., Симоненко В.Г., Трушков В.Г., Хабибуллин М.В. Шиповский И.Е., Шуталев В.Б. // Изв. вузов. Физика. 1992. № 8. С. 5-48.

[32] Буркин В.В., Дьячковский А.С., Корольков Л.В., Егоров А.Л., Майстренко И.В., Степанов Е.Ю., Чупашев А.B., Рогаев К.С. Датчик дульной скорости. Патент на полезную модель № 161396. Заявка № 2015127042. Приоритет от 06.07.2015 г. 